\title{
The potential effect of the UK 1990 height centile charts on community growth surveillance
}

\author{
A M Cotterill, W H Majrowski, S Hearn, S Jenkins, M A Preece, M O Savage
}

\begin{abstract}
The UK 1990 height charts are derived from an up to date dataset and introduce a change in the centile lines, particularly the addition of the 0.4 th centile. This study examined the likely impact of these changes. Height data from London school children (1990-1993) were examined using Tanner and Whitehouse (TW) and UK 1990 charts. Numbers of children with height below TW 3rd centile were compared with numbers below the UK 1990 3rd and $0 \cdot 4$ th centiles. The TW charts identified only $1 \%$ of children below the TW 3rd centile, while the UK 1990 charts identified $3 \%$ below the 3 rd and $0.4 \%$ below the 0.4 th centiles. If the 3 rd centile remains as the referral 'cut off' for short stature, the introduction of the UK 1990 charts would increase current workload two- to threefold, while a change to the 0.4 th centile would reduce it by $50 \%$. A significant number of children with abnormalities may be excluded from further assessment as a result of this latter change. In this small scale community study it is not possible to assess the consequences of this change. The heights at diagnosis of children with growth hormone (GH) deficiency (peak GH $<20 \mathrm{mU} / \mathrm{l}$ during a standard provocation test) were therefore compared to the 0.4th centile (UK 1990 charts). Sixty eight children with heights <2nd centile (UK 1990 charts) currently receiving GH replacement (17 female, 51 male, aged 9.7 , SD 3.5 , years) were assessed, and of these, $28(41 \%)$ had heights at diagnosis between 0.4 th and 2 nd centile, with a mean height standard deviation score of $-2 \cdot 32$ (SD $0 \cdot 21$ ). This suggests that if the 0.4 th centile were to be used as the sole criterion for referral for slow growth, a significant proportion of children with abnormality would not be referred for further assessment. The UK 1990 2nd centile should replace the TW 3rd centile. Children below this should undergo an intermediary medical assessment to confirm height measurement, to exclude from referral children with mild familial short stature and to identify concerns regarding the child.

(Arch Dis Child 1996; 74: 452-454)
\end{abstract}

Keywords: height, centile charts, short stature, community surveillance.

Correspondence to: Dr A M Cotterill, Division of Paediatric Endocrinology,

Department of

Endocrinology,

St Bartholomew's Hospital,

London EC1A 7BE.
Revised cross sectional stature curves for children in the United Kingdom have recently been published, which introduce new height centile charts for clinical use. ${ }^{12}$ Using the compilation of a number of datasets from across the United Kingdom, nine centile lines spaced at 0.67 standard deviation (SD) intervals now replace the original centiles of Tanner and Whitehouse (TW) ${ }^{3}$ It has been suggested that in these cross sectional data charts, the lowest centile $(0.4 \mathrm{th})$, that is, $-2.67 \mathrm{SD}$, should be used as a more practical 'cut off' for growth surveillance programmes than the current TW 3rd centile. ${ }^{2}$ The purpose of this report is to assess the potential effects of such changes on community height surveillance.

This study is based on the examination of a dataset collected by school nurses in the inner city area of the London Borough of Hackney between 1990 and 1993. ${ }^{4}$ The three questions asked were first, do the UK 1990 charts more accurately represent the current child population of Hackney than the TW charts? Second, if it is appropriate to use the new charts, what would be the effect of the change from TW charts to the new growth charts on the workload of community health workers? Last, what would be the effect on the referral of children with short stature if the cut off for referral were changed from the 3 rd to the $0 \cdot 4$ th centile?

\section{Methods}

Heights of children were measured by a school nurse at school entry examinations at age 5 years or 11 years. ${ }^{4} \mathrm{~A}$ free standing technique using a minimeter was employed. ${ }^{5} 6$ The name, date of birth, sex, date of measurement, and height of the child were recorded. The accuracy and reproducibility of the nurses' measurements were satisfactory. ${ }^{5}$ The height data were compared with the TW 3rd centile, UK 1990 3rd centile, and UK 1990 0.4th centile. Children with height less than these cut off points were identified.

The number of children with heights below the 3rd centile on TW charts was compared with the number of children with heights below the 3rd on UK 1990 charts in order to assess the appropriateness of the respective charts for the current child population in Hackney. The number of children with heights below the 3rd centile on the UK 1990 charts was then compared with the number of children with heights below the 0.4 th centile, that is, the numbers of children likely to be referred using the old and the new referral criteria were compared.

A change from the $3 \mathrm{rd}$ centile to the 0.4 th centile as a cut off for referral may have important effects on the identification of children with significant abnormality. This is difficult to assess in a local community study, given the 
Table 1 Five year old children in Hackney identified for referral using either TW or UK 1990 charts

\begin{tabular}{|c|c|c|c|c|c|}
\hline \multirow[b]{2}{*}{ Charts used } & \multirow{2}{*}{$\begin{array}{l}\text { Centile } \\
\text { used }\end{array}$} & \multicolumn{2}{|c|}{ Boys $(n=4210)$} & \multicolumn{2}{|c|}{ Girls $(n=4062)$} \\
\hline & & $n$ & $\%$ & $n$ & $\%$ \\
\hline $\begin{array}{l}\text { Tanner } \\
\text { Whitehouse }\end{array}$ & 3 rd & 49 & $1 \cdot 2$ & 41 & $1 \cdot 0$ \\
\hline UK 1990 & $\begin{array}{l}3 \text { rd } \\
0.4 \text { th }\end{array}$ & $\begin{array}{r}110 \\
20\end{array}$ & $\begin{array}{l}2 \cdot 6 \\
0 \cdot 48\end{array}$ & $\begin{array}{r}136 \\
19\end{array}$ & $\begin{array}{l}3 \cdot 3 \\
0 \cdot 47\end{array}$ \\
\hline
\end{tabular}

low incidence of conditions such as growth hormone $(\mathrm{GH})$ deficiency $(1: 4000) .{ }^{7}$ We therefore examined the heights at diagnosis of children with GH deficiency currently attending the paediatric endocrinology clinic which serves the Hackney population. Children with short stature (height $<2$ nd centile UK Height Standards 1990) and classical GH deficiency (peak $\mathrm{GH}<20 \mathrm{mU} / \mathrm{l}$ on a standard provocation test) were identified. Their heights at diagnosis were compared to the UK height standards and converted to height standard deviation scores (SDS). The children were divided according to the 0.4 th centile and the characteristics of those with height $>0.4$ th centile were compared to those with heights $<0 \cdot 4$ th centile.

\section{Results}

The effect of using UK 1990 charts compared to TW charts on the number of short children, that is, height below the $3 \mathrm{rd}$ centile, is shown in tables 1 and 2. The use of the UK 1990 3rd centile shows that the number of 5 year old children identified as needing referral would increase from 90 ( $1 \%$ of the population) to 246 $(3 \%)$. Similarly, the number of 11 year olds identified would increase from $84(2.4 \%$ of the population) to $144(3 \cdot 8 \%)$.

If the $0 \cdot 4$ th centile were used to identify children with short stature rather than the 3rd centile, then the number of referrals would fall from 246 to 39 children $(0 \cdot 47 \%)$ aged 5 years and from 144 to 15 children (0.39\%) aged 11 years.

Sixty eight children (17 female, 51 male), aged 9.7 (SD 3.5) years with short stature ( $<2$ nd centile UK height standards 1990) and GH deficiency [peak GH 11.9 (4.9) (range 1.9 to $19 \cdot 6)$ ] were identified as currently attending the paediatric endocrine clinic. Twenty eight children had heights at diagnosis $>0.4$ th centile with a mean height SDS of -2.32 $(0 \cdot 21)(-2 \cdot 0$ to $-2 \cdot 67)$. Forty children with height $<0.4$ th centile had a mean height SDS of $-3 \cdot 17(0 \cdot 44)(-2 \cdot 70$ to $-4 \cdot 15)$. There was no significant difference in the peak GH level achieved during provocation testing [height $>0.4$ th centile $12.5(4.4) \mathrm{mU} / \mathrm{l}$; height $<0.4$ th centile $11.5(5 \cdot 3) \mathrm{mU} / 1$ ]

Table 2 Eleven year old children in Hackney identified for referral using either TW or UK 1990 charts

\begin{tabular}{|c|c|c|c|c|c|}
\hline \multirow[b]{2}{*}{ Charts used } & \multirow{2}{*}{$\begin{array}{l}\text { Centile } \\
\text { used }\end{array}$} & \multicolumn{2}{|c|}{ Boys $(n=1754)$} & \multicolumn{2}{|c|}{ Girls $(n=2048)$} \\
\hline & & $n$ & $\%$ & $n$ & $\%$ \\
\hline $\begin{array}{l}\text { Tanner } \\
\text { Whitehouse }\end{array}$ & 3 rd & 42 & $2 \cdot 4$ & 42 & $2 \cdot 1$ \\
\hline UK 1990 & $\begin{array}{l}3 \mathrm{rd} \\
0 \cdot 4 \text { th }\end{array}$ & $\begin{array}{r}84 \\
8\end{array}$ & $\begin{array}{l}4 \cdot 68 \\
0 \cdot 46\end{array}$ & $\begin{array}{r}60 \\
7\end{array}$ & $\begin{array}{l}2.9 \\
0.34\end{array}$ \\
\hline
\end{tabular}

\section{Discussion}

This study shows that the UK 1990 charts accurately represent the distribution of height in this inner city population, and that the use of the TW charts for this population is no longer appropriate. ${ }^{1}$ The correct percentage of children lie below the 3rd centile for height. The UK 1990 charts indicate a general increase in height of the population since the TW charts were established in the $1960 \mathrm{~s}^{13}$

A simple change from the TW 3 rd centile to the UK 1990 3rd centile as a cut off for referral of short stature by community health workers would result in a two- to threefold increase in workload. Cole has suggested a change for the cut off used for referral for the assessment of short stature from $3 \%$ to $0.4 \%$ of the population. ${ }^{2}$ Clearly, since the UK 1990 charts represent the height of the current child population, there would be a reduction in referral rates for investigation of children from $3 \%$ to $0.4 \%$ of the population. If the UK 1990 height centile charts were used for screening the general population to identify children with short stature associated with significant abnormality, this step would markedly improve the specificity of height surveillance programmes.

It must be appreciated, however, that the 0.4 th centile represents a more severe degree of short stature, that is, $-2.67 \mathrm{SD}$. If this bottom line on the UK 1990 charts comes to be regarded in the same way as the TW 3rd centile, that is, children with heights above this line are not referred, a significant number of children with pathological conditions may be excluded from further assessment.

The extent of this shortfall is difficult to assess directly in the present community based project, given the low incidence of organic disease. For instance, in order for a community surveillance programme to identify 70 children with GH deficiency about 250000 children would have to be assessed. ${ }^{7}$ We have therefore addressed this point indirectly by examining the height at diagnosis of children with short stature and classical GH deficiency. Forty one per cent of the children had heights at diagnosis above the 0.4 th centile. This figure could be considered as an initial estimate of the false negative rate if the UK Height Standard 1990 0.4th centile were now to be used as the sole criterion for referral. Further studies are required to address this point in more detail.

We therefore suggest that the UK 1990 2nd centile should be used in most circumstances as the cut off for judging normality. A second confirmatory measurement, with assessment of parental target range, should then be performed, together with a full medical assessment. ${ }^{4}$ Although this would impair specificity we feel that sensitivity of detection of abnormality would be improved.

We suggest that general practitioners and community health workers should assess all children with height below the 2 nd centile. When height is below the 0.4 th, we advise referral. If height is between 0.4 th and 2 nd centiles, referral should be considered where 
there is professional or parental concern or where there is discrepancy between parental target centile and the child's centile.

In conclusion, the introduction of the UK 1990 height charts together with a change from the TW 3rd centile to the UK 1990 2nd centile as the cut off for referral will lead to a 1.5- to twofold increase in workload for community services. We suggest that an intermediary medical assessment is performed to further improve specificity and sensitivity of height surveillance programmes in relation to short children. This would confirm height measurement, identify concerns regarding the child, and exclude from referral children with mild familial short stature. This process needs to be reviewed in the near future.
1 Freeman JV, Cole TJ, Chinn S, Jones PRM, White EM, Preece MÁ. Cross-sectional stature and weight reference curves for the UK, 1990. Arch Dis Child 1995; 73: 17-24. 2 Cole TJ. Do growth charts need a face lift? BMF 1994; 308: 641-2.

3 Tanner JM, Whitehouse RH, Takaishi M. Standards from birth to maturity for height, weight, height velocity, and weight velocity: British children, 1965. Parts I and II. Arch Dis Child 1966; 41: 454-71, 613-35.

Hearn S, Cotterill AM, Majrowski W, Rohan C, Jenkins S, Savage MO. The construction of a community height screening programme: The Hackney Growth Initiative. f Med Screening 1995; 2: 157-9.

5 Cotterill AM, Majrowski WH, Hearn S, Jenkins S, Savage MO. Assessment of the reliability of school nurse height measurements in an inner city population (The Hackney Growth Initiative). Child Care Health Dev 1993; 19: 159-65.

6 Majrowski WH, Hearn S, Rohan C, Jenkins S, Cotterill AM, Savage MO. Comparison of school nurse and auxologist height velocity measurements in school children with short
stature (The Hackney Growth Initiative). Child Care Health Dev 1994; 20: 179-88.

7 Vimpani V, Vimpani AF, Ligard GP, Cameron EGD, Farquhar $\mathrm{JW}$. Prevalence of severe growth hormone deficiency. BMF 1977; ii: 427-8. 